$\beta$-glycerol phosphate. This separation is shown in Table 1, where most of the phosphoprotein phosphatase and some of the phenyl phosphatase activity of $A_{0}$ appears in $B_{1}$, whereas all the $\beta$ glycerol phosphatase activity is found in $A_{1}$. The last-named enzyme has not been further studied, but it would clearly be desirable to investigate its properties.

\section{SUMMARY}

1. An improved method for the preparation of phosphoprotein phosphatase from ox spleen is described. The enzyme was purified 60 -fold with a yield of $21 \%$.

2. The enzyme preparation was free from proteolytic activity and had no action on $\beta$-glycerol phosphate.

3. The enzyme was active on caseins, phenyl phosphate and inorganic pyrophosphate. Hence it cannot be described as a specific phosphoprotein phosphatase.

4. The $\mathrm{pH}$ optimum with caseins and phenyl phosphate was about $\mathrm{pH} 5 \cdot 5$.

5. The enzyme was stable over a wide range of pH and at temperatures below $70^{\circ}$.

The author wishes to thank Miss M. Cummings and Miss E. S. Taylor for technical assistance, and also Imperial Chemical Industries Ltd. (Dyestuff Division) for a generous sample of Naphthalene Black 12B 200.

\section{REFERENCES}

Berenblum, I. \& Chain, E. (1938). Biochem. J. 32, 295.

Dunn, M. S. (1949). Biochem. Prep. 1, 22.

Feinstein, R.N. \& Volk, M.E.(1949). J.biol.Chem.177, 339.

Fiske, C. H. \& Subbarow, Y. (1925). J. biol. Chem. 66, 375.

Flynn, F. V. \& De Mayo, P. (1951). Lancet, 2, 235.

Foote, M. W. \& Kind, C. A. (1953). Arch. Biochem. Biophys. 46, 254.

Harris, D. L. (1946). J. biol. Chem. 165, 541.

Hiller, A., Plazin, J. \& Van Slyke, D. D. (1948). J. biol. Chem. 176, 1401.

Hofman, T. (1955). Abstr. 3rd Int. Congr. Biochem., Brussels, p. 26, nos. 4-9.

Hofman, T. (1958). Biochem. J. 69, 139.

Latner, A. L. (1952). Biochem. J. 51, xii.

Lineweaver, H. \& Burk, D. (1934). J. Amer. chem. Soc. 56, 658.

Martin, J. B. \& Doty, D. M. (1949). Analyt. Chem. 21, 965.

Mattenheimer, H., Nitschmann, H. \& Zahler, P. (1952). Helv. chim. acta, 35, 1970.

Morton, R. K. (1953). Biochem. J. 55, 795.

Norberg, B. (1950). Acta chem. scand. 4, 1206.

Roche, J., Thoai, N-V. \& Pin, P. (1953). C.R Soc. Biol., Paris, 147, 409.

Roche, J., Thoai, N.V. \& Thiêm, N. V. (1952). C.R. Soc. Biol., Paris, 146, 227.

Sundararajan, T. A. \& Sarma, P. S. (1954a). Biochem. J. $56,125$.

Sundararajan, T. A. \& Sarma, P. S. (1954b). Biochim. biophys. Acta, 13, 588.

Thoai, N.V., Roche, J. \& Pin, P. (1954). Bull. Soc. Chim. biol., Paris, 36, 483.

\title{
Studies on Casein
}

\section{THE ACTION OF PHOSPHATASES ON CASEINS AND LOW-MOLECULAR-WEIGHT PHOSPHATES*}

\author{
By T. HOFMAN† \\ Hannah Dairy Research Institute, Kirkhill, Ayr
}

(Received 29 November 1957)

Although a number of studies on the nature of the phosphorus linkages in phosphoproteins and in caseins in particular have been made during the past 30 years, no definite conclusions about the site and nature of the phosphorus linkages can as yet be drawn. That the phosphorus may be linked to the hydroxyamino acids serine and threonine was suggested by the isolation of $O$-serine phosphate by Lipmann (1933) and $O$-threonine phosphate by de Verdier (1953). However, the isolation procedure of these compounds did not exclude the possibility that the phosphate group had migrated

* Part 1: Hofman (1958a).

$\dagger$ Present address: Department of Biochemistry, University of Sheffield. to the hydroxyl group of serine and threonine during hydrolysis. This was suggested by Plapinger \& Wagner-Jauregg (1953), who showed that serine phosphorylated with a diisopropyl phosphate residue on the amino group was converted on hydrolysis into $O$-serine phosphate. A number of authors (see review by Perlmann, 1955) prepared, from enzymically degraded casein, phosphopeptones which always contained serine and phosphate groups with a varying number of other acids. New interest was aroused in the nature of the phosphorus linkages in caseins by the findings of Perlmann (1952b). This author employed phosphatases to remove, selectively, the phosphate groups from ovalbumin, caseins and pepsin. 
During the course of the present study a detailed account was published by Perlmann (1954a,b), which suggested the presence of phosphomonoester, mixed phosphoamide ester and pyrophosphate linkages in $\alpha$-casein and phosphodiester linkages in $\beta$-casein. The enzymes prostate phosphatase, intestinal phosphatase, snake-venom phosphodiesterase and yeast pyrophosphatase were used in that study. In the present work the action of phosphoprotein phosphatase from ox spleen on caseins and a number of low-molecular-weight phosphates has been studied. In addition, the action of prostate phosphatase on caseins has been reinvestigated. As will be shown, the results do not support the findings of Perlmann.

A preliminary account of some of these results has been given (Hofman, 1955).

\section{MATERIALS AND METHODS}

\section{Enzymes}

Phosphoprotein phosphatase. The purified preparation $B_{1}$ described in the preceding paper (Hofman, 1958 a) was used throughout.

Prostate phosphatase. Human prostate glands, which had been removed because of benign hyperplasia, were used as starting material. In some experiments an extract of sliced glands, prepared according to London \& Hudson (1953) with $0 \cdot 2 \mathrm{M}$-acetic acid-sodium acetate buffer, $\mathrm{pH} 5 \cdot 9$, was used after it had been dialysed. This is referred to below as the 'unpurified enzyme'. A 'purified enzyme' preparation was made partly according to London \& Hudson (1953). The dialysed extract was treated with calcium phosphate gel as described by these authors. From this step onwards the following procedure was adopted in preference to the method of these authors because of its simplicity, since the main purpose of the purification was to remove all proteolytic enzymes. Ammonium sulphate $(7 \cdot 26 \mathrm{~g}$.) was added to the eluate from the calcium phosphate gel $(30 \mathrm{ml}$.) to $40 \%$ saturation. The inactive precipitate obtained by centrifuging was discarded. The supernatant $(34 \mathrm{ml}$.) was brought to $80 \%$ saturation with $9 \cdot 66 \mathrm{~g}$. of ammonium sulphate. The precipitate containing most of the activity was centrifuged off, dissolved in $10 \mathrm{ml}$. of water and dialysed in the cold until it was free of ammonium sulphate. The solution $(17 \mathrm{ml}$.) was then treated with $23 \mathrm{mg}$. of alumina gel $\mathrm{C}_{\gamma}$ in $2 \mathrm{ml}$. of water to adsorb the enzyme. After the gel had been washed with water, the enzyme was eluted with $15 \mathrm{ml}$. of $0.005 \mathrm{M}$ sodium citrate buffer, $\mathrm{pH}$ 7. Most of the activity was found in the eluate. This solution was used as the purified enzyme. When it was incubated for $24 \mathrm{hr}$. at $37^{\circ}$ with haemoglobin (according to Anson, 1938) no proteolysis could be detected.

\section{Substrates}

Caseins. Fresh, pooled skim milk from Ayrshire cows or from British Saanen goats was used as starting material for the preparation of unfractionated caseins essentially according to Dunn (1949). From these the $\alpha$ - and $\beta$-caseins were prepared by the method of Warner (1944). Although unfractionated goat's casein contains considerably more $\beta$-casein and less $\alpha$-casein than cow's casein (Dovey \&
Campbell, 1952), they could easily be separated by Warner's method. For the goat caseins elementary analysis gave the following figures (on an ash- and moisturefree basis) : $\alpha$-casein, $N, 15 \cdot 5 ; \mathrm{P}, 1.02 \% ; \beta$-casein, $\mathrm{N}, 15 \cdot 3$; $\mathrm{P}, 0.61 \%$. These figures agree well with the published figures for pure $\alpha$ - and $\beta$-casein from cow's milk (Hipp, Groves, Custer \& McMeekin, 1952), indicating that the goat proteins may be very similar to those of the cow.

Recently it has been shown that cow's and goat's $\alpha$ caseins are not homogeneous, but consist of at least two proteins (Waugh \& Hippel, 1956; Hofman, 1958b). However, it is thought that this does not affect the conclusions which can be drawn from the present work.

All the caseins were dried with alcohol and ether for storing.

Phosphopeptone. A small amount of Rimington's phosphopeptone (Rimington, 1927) was available. No study of its structure was possible, but qualitative amino acid analysis by paper chromatography showed that it consisted largely of serine and glutamic acid with smaller amounts of alanine, aspartic acid, glycine, valine and leucine or isoleucine. The phosphorus content of the peptone was $7 \cdot 32 \%$, which agreed well with the figure of $\mathbf{7 \cdot 4 4} \%$ obtained by Rimington (1941).

Non-protein substrates. Diphenyl phosphate and di- $(p-$ nitrophenyl) phosphate were synthesized by the method of Plumel (1948). They were at least $97 \%$ pure. $O$-Tyrosine phosphate was prepared according to Plimmer (1941) in over $95 \%$ purity, $O$-serine phosphate and $O$-threonine phosphate according to Plapinger \& Wagner-Jauregg (1953) in about $90 \%$ purity. $N$-Phosphoalanine was kindly prepared as a hydrated magnesium salt by the method of Winnick \& Scott (1947) by Dr W. Manson. $s$-Diphenyl pyrophosphate was prepared as the dicyclohexylamine salt, as described by Khorana \& Todd (1953), with over $95 \%$ purity. The lithium salt of acetyl phosphate of $75 \%$ purity was a gift from Dr J. L. Peel, and the $N$. (phenylphosphoro)glycine a gift from Dr R. S. Wake. The purity of all these compounds was assessed by melting point, phosphorus analysis, nitrogen analysis (where appropriate) and paper chromatography.

All other compounds were commercial products whose purity was not assessed.

\section{Conditions of incubation}

Experiments with phosphoprotein phosphatase. Except where otherwise stated, $3.5 \mathrm{~mm}$ solutions of the substrates in $0.1 \mathrm{M}$-acetate, $\mathrm{pH} 5.9$, were incubated at $37^{\circ}$ for varying intervals with suitable amounts of enzyme and thioglycollic acid to give the final concentrations of $2.7 \times 10^{-3} \mathrm{~g}$. atoms of substrate phosphorus/l. and mm-thioglycollic acid. The amount of enzyme was chosen so that not less than $10 \%$ of the substrate was hydrolysed in $2 \mathrm{hr}$. except where there was virtually no action on the substrate. The reaction was stopped by the addition of $1 \mathrm{ml}$. of $0.02 \mathrm{M}$-silicotungstic acid and $2 \mathrm{ml}$. of $23 \%$ (w/v) trichloroacetic acid to samples (1 ml.) of the incubation mixture. The inorganic phosphate was then determined according to the method of Martin \& Doty (1949). When caseins were used as substrates samples ( $2 \mathrm{ml}$.) of the incubation mixture were treated with $2 \mathrm{ml}$. of $0.02 \mathrm{M}$-silicotungstic acid and $4 \mathrm{ml}$. of $23 \%(\mathrm{w} / \mathrm{v})$ trichloroacetic acid. The precipitate was centrifuged off and the inorganic phosphate determined on $4 \mathrm{ml}$. of the supernatant. 
For the estimation of the hydrolysis of $N$-phosphoalanine a modified method had to be used because of the extreme lability of the compound. Preliminary experiments showed that the compound was hydrolysed extremely rapidly when in contact with trichloroacetic acid and molybdate for only a few seconds. An indirect method of analysis was therefore used. A sample $(2 \mathrm{ml}$.) of the incubation mixture was added to $2 \mathrm{ml}$. of a solution of $10 \%(\mathrm{w} / \mathrm{v})$ calcium chloride in $0.5 \mathrm{M}$-ammonium chloride at $\mathrm{pH} 9$ and $0^{\circ}$ (Norberg, 1950). After standing for $30 \mathrm{~min}$. at $0^{\circ}$, the inorganic phosphate had precipitated as calcium phosphate and was centrifuged off. A volume $(1 \mathrm{ml}$.) of the supernatant was then added to $1 \mathrm{ml}$. of $0.02 \mathrm{M}$-silicotungstic acid and $2 \mathrm{ml}$. of $23 \%(\mathrm{w} / \mathrm{v})$ trichloroacetic acid and the mixture was kept for $30 \mathrm{~min}$. at $37^{\circ}$. This hydrolysed the remaining phosphoalanine to alanine and inorganic phosphate which was then estimated.

Experiments with prostate phosphatase. These were carried out in a way similar to that described for phosphoprotein phosphatase except that no activator was added. Both purified and unpurified enzymes were used. The substrate concentration in the final incubation mixture varied between $\mathrm{mm}$ and $20 \mathrm{~mm}$. In all experiments which lasted more than $2 \mathrm{hr}$. chloroform and thymol were used as antiseptics.

\section{RESULTS}

\section{Phosphoprotein phosphatase}

The action of this enzyme preparation on a number of substrates is shown in Table 1 . It is evident that the enzyme is very active towards compounds in which the phosphate group is esterified with a phenolic hydroxyl group. Aliphatic monoesters were virtually not hydrolysed, with the exception of the ribonucleotides. The action on the ribonucleotides could be due to the presence of a specific nucleotidase as an impurity.

The action of the enzyme on phosphodiesters and on a mixed amide ester [ $N$-(phenylphosphoro)glycine] was negligible.

The enzyme preparation rapidly hydrolysed inorganic pyrophosphate and also adenosine triphosphate, which was converted into adenosine monophosphate and inorganic phosphate. On the other hand, when both phosphate groups in the pyrophosphate molecules were esterified, as in diphenyl pyrophosphate and diphosphopyridine nucleotide, no hydrolysis took place. One of the most striking features was the very high activity of the enzyme towards acetyl phosphate.

It is not surprising that the enzyme also acted on phosphoamides, because all non-specific phosphomonoesterases so far studied have displayed some phosphoamidase activity (Møller, 1955). The enzyme acted not only on $p$-chloroanilidophosphate, a standard substrate for the assay of phosphoamidase activity, but also on $N$-phosphoalanine. Owing to the lability of this compound under the conditions of the experiment at $\mathrm{pH} \mathbf{5 . 9}$, no initial rates of enzymic hydrolysis could be determined, but Fig. 1 clearly demonstrates that the compound was hydrolysed by the enzyme.

The action of the enzyme on the phosphate linkage in casein molecules was investigated in some detail. Fig. 2 gives a typical example of a timehydrolysis curve obtained on incubating cow's

Table 1. Action of phosphoprotein phosphatase on phosphate esters

Initial rates of hydrolysis were determined as described under Materials and Methods. The activity is expressed relative to the activity (100) of the enzyme towards cow's $\boldsymbol{x}$-casein.

\section{Caseins}

Relative activity

Unfractionated, cow

Unfractionated, goat

81

$\alpha$-Casein, cow

64

$\alpha$-Casein, goat

100

$\beta$-Casein, cow

114

$\beta$-Casein, goat

90

114

Phosphopeptone

52

\section{Phosphomonoesters}

Aromatic

Phenyl phosphate

$p$-Nitrophenyl phosphate

$O$-Tyrosine phosphate

200

Aliphatic

$\alpha$-Glycerol phosphate

$\beta$-Glycerol phosphate

Glucose 6-phosphate

Glucose 1-phosphate

Ribose 5-phosphate

$O$-Serine phosphate

$O$-Threonine phosphate

Adenosine 5' -phosphate

Adenosine 3'-phosphate

Uridine $3^{\prime}$-phosphate

Guanidine 3'-phosphate

Cytidine 3'-phosphate

$>400$

155

Phosphoamides

$p$-Chloroanilidophosphate

$N$-Phosphoalanine

0.25

$0 \cdot 6$

$0 \cdot 79$

$0 \cdot 1$

0.64

0.45

$0 \cdot 14$

4

16

15

21

$0 \cdot 16$

$11 \cdot 5$

Phosphodiesters

Diphenyl phosphate

Di-( $p$-nitrophenyl) phosphate

$N$-(Phenylphosphoro)glycine

Pyrophosphates

Inorganic pyrophosphate

Adenosine triphosphate $\rightarrow$ adenosine

monophosphate

$s$-Diphenyl pyrophosphate

Diphosphopyridine nucleotide

Acetyl phosphate

117

Fast

$0.74 \dagger$

$0.89 \ddagger$

900

* Owing to considerable spontaneous hydrolysis no quantitative estimation of the initial rate of enzymic hydrolysis was possible (see also Fig. 2).

$\dagger$ Hydrolysis was determined by estimation of inorganic phosphate and phenol and $\boldsymbol{p}$-nitrophenol respectively.

$\ddagger$ Assayed spectrophotometrically with alcohol dehydrogenase. 
casein with the enzyme. It shows that a complete removal of the phosphate groups was effected readily. Similar results were obtained with other caseins (Table 2). These findings agree well with those of Sundararajan \& Sarma (1954b) who found that phosphoprotein phosphatase from rat's

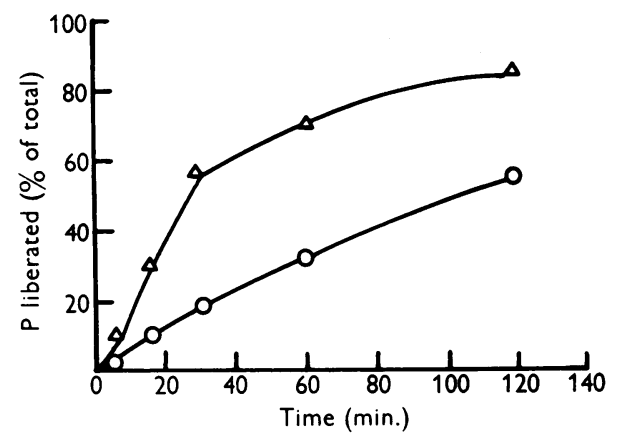

Fig. 1. Hydrolysis of $N$-phosphoalanine by phosphoprotein phosphatase. Incubation was at $37^{\circ}$, in $0.1 \mathrm{M}$-acetate buffer, pH 5.9, with $N$-phosphoalanine (3 mM) as substrate. $\triangle$, Hydrolysis by phosphoprotein phosphatase; $\bigcirc$, spontaneous hydrolysis.

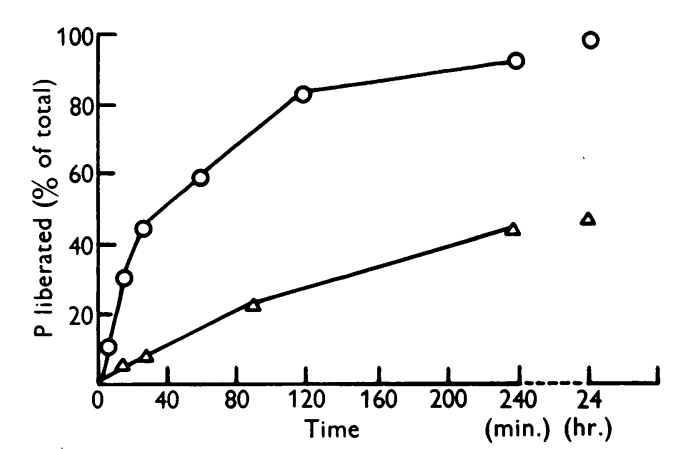

Fig. 2. Hydrolysis of cow $\alpha$-casein and phosphopeptone by phosphoprotein phosphatase. Experimental conditions were as described under Materials and Methods; substrate concentration was equivalent to $3 \times 10^{-8} \mathrm{~g}$. atoms of phosphorus/l. $O, \alpha$-Casein; $\Delta$, phosphopeptone.

\section{Table 2. Hydrolysis of caseins by phosphoprotein phosphatase}

Experimental conditions were as described under Materials and Methods. Substrate concentrations were equivalent to $3 \times 10^{-3} \mathrm{~g}$. atoms of phosphorus $/ 1$.

$\begin{array}{llc}\text { Source } & \text { Type of casein } & \text { after 6-24 hr. } \\ \text { Cow } & \text { Unfractionated } & 94 \\ \text { Cow } & \alpha- & 96 \\ \text { Cow } & \beta- & 89 \\ \text { Goat } & \text { Unfractionated } & 92 \\ \text { Goat } & \alpha- & 102 \\ \text { Goat } & \beta- & 96\end{array}$

Table 3. Action of purified prostate phosphatase on phospho compounds

Incubations were carried out at substrate concentrations equivalent to $1.3 \times 10^{-2} \mathrm{~g}$. atoms of phosphorus/l. in $0 \cdot 1 \mathrm{M}$ acetate, $\mathrm{pH} 5.9$, and $37^{\circ}$. To $0.9 \mathrm{ml}$. of substrate were added the following amounts of the 'purified enzyme' (see Materials and Methods): for $\beta$-glycerol phosphate, phenyl phosphate and tyrosine phosphate, $0.5 \mu \mathrm{l}$; for serine phosphate and threonine phosphate, $1 \mu \mathrm{l}$; for phosphopeptone, $25 \mu \mathrm{l}$., and for casein, $200 \mu \mathrm{l}$. Incubation times varied between $10 \mathrm{~min}$. and $4 \mathrm{hr}$.

$\begin{array}{lc}\text { Phenyl phosphate } & 880 \\ O \text {-Tyrosine phosphate } & 1100 \\ \beta \text {-Glycerol phosphate } & 500 \\ O \text {-Serine phosphate } & 55 \\ O \text {-Threonine phosphate } & 50 \\ \text { Phosphopeptone } & 1 \cdot 3 \\ \text { Caseins } & 0 \cdot 07-0 \cdot 7^{*}\end{array}$

* Owing to the very slow release of phosphate these values are only approximate.

spleen readily splits all the phosphate from cow's $\alpha$ - and $\beta$-casein. The present enzyme removed only $50 \%$ of the phosphate from each of two phosphopeptones one of which contained $7 \cdot 32 \%$ of phosphorus and the other $3.8 \%$. This finding contrasts with that of Sundararajan \& Sarma $(1954 a)$ who showed that their purified enzyme had no appreciable action on a phosphopeptone.

\section{Prostate phosphatase}

It has been claimed by Perlmann (1952a) that this non-specific phosphomonoesterase liberates $40 \%$ of the phosphorus from $\alpha$-casein and no phosphorus from $\beta$-casein, thus indicating that $40 \%$ of the phosphate in $\alpha$-casein is in the form of a phosphomonoester. We repeated these experiments and found that the action of this enzyme was extremely slow. Table 3 gives the relative activity of a purified preparation of prostate phosphatase on various caseins and some low-molecular-weight phosphates. It shows that the enzymic release of phosphate from the low-molecular-weight phosphates was between $10^{2}$ and $10^{4}$ times as fast as that from casein. Similar results were obtained with veronal-acetate and citrate buffers over $\mathrm{pH} 5 \cdot 0-6 \cdot 5$, the range which covers the optimum $\mathrm{pH}$ of prostate phosphatase. A number of other casein preparations gave similar results, with the exception of cow $\beta$-casein which, in agreement with Perlmann (1952 $a$ ), was not attacked. Table 3 also confirms the findings of Strickland, Thompson \& Webster (1956) that prostate phosphatase is considerably more active towards $\beta$-glycerol phosphate 
and phenyl phosphate than towards serine phosphate and threonine phosphate. That the low activity of the enzyme towards casein was not due to inhibition of the enzyme by the caseins was shown in an experiment in which phenyl phosphate was incubated with the enzyme in the presence of casein. No change in the rate of hydrolysis occurred.

The amount of phosphate which could be released from $\alpha$-casein by incubation for $24 \mathrm{hr}$. under the conditions of Table 3 varied with different casein preparations and was usually between 20 and $46 \%$. Bohren (1955) found that under the experimental conditions of Perlmann (1952a) only $20 \%$ of the casein phosphorus was liberated.

Prolonged incubation of cow $\alpha$-casein, with repeated additions of fresh enzyme of high activity, showed that approximately $40 \%$ of the total phosphorus was liberated (Fig. 3). Although the rate of hydrolysis decreased with time it never seemed to reach a value of zero, indicating that if the experiment could be carried on for a sufficiently long period considerably more of the phosphate might be released. No measurable proteolysis occurred during these experiments.

It was not expected that additions of fresh enzyme would accelerate the hydrolysis because it was found that after incubating the enzyme with casein for $24 \mathrm{hr}$. at $37^{\circ}$ no reduction in activity towards phenyl phosphate had taken place. It was found that casein actually had a protective effect on the enzyme, which in the absence of casein lost $70 \%$ or more of its activity on incubation for $24 \mathrm{hr}$. at $37^{\circ}$. When caseins were incubated with the unpurified enzyme, the release of phosphate was even slower than with the purified enzyme. In these respects no differences were observed between the caseins from cow's and goat's milk.

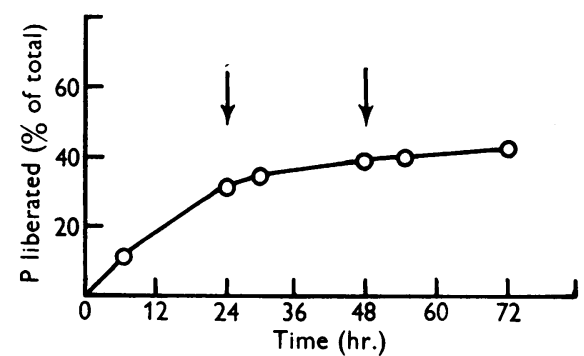

Fig. 3. Hydrolysis of $\alpha$-casein by prostate phosphatase. Incubations were in $0.1 \mathrm{M}$-acetate buffer, $\mathrm{pH} 5.9$, at $37^{\circ}$, with substrate concentration equivalent to $3 \cdot 6 \times 10^{-3} \mathrm{~g}$. atoms of phosphorus/l.; $6 \mathrm{ml}$. of casein solution was mixed with $1.2 \mathrm{ml}$. of purified enzyme. At the times indicated by the arrows an additional $0.2 \mathrm{ml}$. of enzyme was added.

\section{DISCUSSION}

The present experiments were designed to provide evidence on two points : first, the type of linkage in which the phosphate group in casein is involved, and second, the amino acids to which it is linked.

The work of Perlmann $(1954 a, b)$ indicates the presence of the following types of phosphate linkages in cow's $\alpha$-casein: monoester

$$
\mathrm{RO} \cdot \mathrm{PO}(\mathrm{OH})_{2}(40 \%) \text {, }
$$

mixed amide-ester

$$
\mathrm{RO} \cdot \mathrm{PO}(\mathrm{OH}) \cdot \mathrm{NHR}(40 \%)
$$

and disubstituted pyrophosphate

$$
\mathrm{RO} \cdot \mathrm{PO}(\mathrm{OH}) \cdot \mathrm{O} \cdot \mathrm{PO}(\mathrm{OH}) \cdot \mathrm{OR}(20 \%),
$$

and, for $\beta$-casein, a diester

$$
\mathrm{RO} \cdot \mathrm{PO}(\mathrm{OH}) \cdot \mathrm{OR}(100 \%) \text {, }
$$

where $R$ represents residues in the peptide chain of casein. On the other hand, the experiments of Thoai, Roche \& Pin (1954) suggest the presence in $\alpha$-casein of diester bonds $(33 \%)$ and monoester bonds $(50 \%)$.

The results obtained in the present work do not support these findings. The experiments with phosphoprotein phosphatase do not indicate more than one type of linkage. If it is justifiable to assume that the specificity of an enzyme is the same whether it acts on phosphate links in small molecules or in large molecules, then the fact that the spleen phosphoprotein phosphatase used in these experiments did not act on phosphodiesters, such as diphenyl phosphate, or on mixed amide esters such as phenylphosphoroglycine or on disubstituted pyrophosphates such as s-diphenyl pyrophosphate and diphosphopyridine nucleotide, indicates that it is unlikely that these types of bonds are present in the caseins. Phosphomonoester to aromatic hydroxyl groups, phosphoamide, monosubstituted pyrophosphate and acyl phosphate bonds are suggested as possibilities by the pattern of specificity (Table 1).

Although the phosphatases used in the studies on casein possess phosphoamidase activity it would appear unlikely that such bonds are to be found in caseins, because they would be expected to be more labile in acid than in alkaline conditions, whereas the phosphate of casein is labile only in alkali (Plimmer \& Bayliss, 1906).

The experiments with phosphoprotein phosphatase suggest that the phosphate might be bound as ester to an aromatic hydroxyl, i.e. that of tyrosine, since the enzyme acts very strongly on such esters but not on aliphatic esters. However, unpublished experiments showed that all the tyrosine hydroxyl groups were free. Use was made in these experiments of the fact that at above $\mathrm{pH} 11$ 
the tyrosine residue undergoes ionization, which leads to changes in the absorption spectra (Crammer \& Neuberger, 1943). These changes do not occur if the hydroxyl group is esterified. It was found that even on complete dephosphorylation of the casein by alkali no change occurred either in the shape of the absorption spectrum or in the extinction, if the experiments were made in guanidine solutions. Some increase in the extinction at 250 and $295 \mathrm{~m} \mu$ was found when the experiments were made in aqueous solution. 'This increase was not observed in the presence of guanidine, which indicates that it was due, not to the removal of the phosphate, but to the breaking of hydrogen bonds in which the tyrosine hydroxyl had been involved.

No indication of the presence of any monosubstituted pyrophosphate residues in the caseins has been obtained.

Some experiments were made to show whether there are any acyl phosphate bonds, i.e. anhydride bonds between the phosphate and a carboxyl group of the protein. Hydroxylamine was allowed to react with casein under various conditions. If any acyl bonds had been present, the hydroxylamine would have been expected to react with the carboxyl group to form a hydroxamic acid with the liberation of inorganic phosphate (cf. Lipmann \& Tuttle, 1945). No inorganic phosphate was liberated even with conditions under which some formation of hydroxamic acids took place. Under these conditions serum albumin and glutamine also formed hydroxamic acids, showing that the amide bonds were responsible for their formation. It will therefore be seen that the only remaining type of bond is that of a monoester.

The only amino acids to which the phosphate group could be bound in an ester bond are serine and threonine, as tyrosine has been ruled out on the evidence of the spectrophotometric experiments. This link was, of course, already postulated by Lipmann (1933). However, as Table 1 shows, phosphoprotein phosphatase has no activity on either serine or threonine phosphate. If these links are indeed present, then it must be assumed that the incorporation into the peptide chain activates the phosphate ester and renders it susceptible to the enzyme. In analogy to this is the lability of the casein phosphorus with alkali. Whereas serine and threonine phosphate are very stable to boiling sodium hydroxide, casein is readily dephosphorylated even at room temperature. The possibility of serine and threonine phosphate links is supported by the isolation of serine phosphate by Lipmann (1933) and threonine phosphate by de Verdier (1953) after extensive enzymic and acid hydrolysis. However, Plapinger \& Wagner-Jauregg (1953) suggested that the phosphate group could have migrated during the hydrolysis from some other site to the hydroxyl group of serine and threonine. In support of this they showed that when serine, which is phosphorylated by a diisopropyl phosphate residue on the amino group,

$$
\left(\mathrm{C}_{3} \mathrm{H}_{7} \cdot \mathrm{O}\right)_{2} \mathrm{PO} \cdot \mathrm{NH} \cdot \mathrm{CH}\left(\mathrm{CO}_{2} \mathrm{H}\right) \cdot \mathrm{CH}_{2} \cdot \mathrm{OH},
$$

is hydrolysed the phosphate migrates to the hydroxyl group giving the monoester $O$-serine phosphate. More recently, however, Rathlev \& Rosenberg (1956) showed that such a migration does not take place if the phosphate group bears two free hydroxyl groups, as in $N$-phosphoserine,

$$
(\mathrm{HO})_{2} \mathrm{PO} \cdot \mathrm{NH} \cdot \mathrm{CH}\left(\mathrm{CO}_{2} \mathrm{H}\right) \cdot \mathrm{CH}_{2} \cdot \mathrm{OH} \text {. }
$$

If therefore the phosphate group is bound to the casein by only one of its hydroxyl groups one would not expect a migration to take place during hydrolysis.

The experiments with prostate phosphatase give little information on the nature of the phosphate links. First, as Table 3 shows, the liberation of phosphate from serine and threonine phosphates was very much more rapid than the liberation of phosphate from caseins. The liberation of phosphate from other phosphomonoesters such as $\beta$ glycerol phosphate and $O$-tyrosine phosphate was greater still. Although, as indeed Perlmann $(1952 a, b)$ found, some $40 \%$ of the phosphate was released in $24 \mathrm{hr}$. this release was not complete but continued for at least 3 days. This low activity of the prostate phosphatase may be attributed either to a non-specific action on the casein phosphate or, which seems more likely, to the relative inaccessibility of the phosphate groups of casein to this enzyme. That part of the phosphate which was not liberated during the time of the experiment might be even less accessible and would therefore be released even more slowly. From this it is clear that prostate phosphatase is an unsuitable enzyme for such a study.

Difficulties in interpreting this kind of experiment have been encountered not only in the present work but also in the work of Perlmann (1954b). An unpublished experiment with purified phosphodiesterase from the venom of Crotalus adamanteus carried out by us showed that this enzyme, which is very active towards diphenyl phosphate, had no activity towards $N$-(phenylphosphoro)glycine,

$$
\mathrm{C}_{6} \mathrm{H}_{5} \cdot \mathrm{O} \cdot \mathrm{PO}(\mathrm{OH}) \cdot \mathrm{NH} \cdot \mathrm{CH}_{2} \cdot \mathrm{CO}_{2} \mathrm{H},
$$

liberating neither phenol nor glycine. This enzyme, however, was used by Perlmann to show the presence of

$$
\mathrm{RO} \cdot \mathrm{PO}(\mathrm{OH}) \cdot \mathrm{NHR}
$$

bonds in $\alpha$-casein. A similar difficulty was met with in an experiment with crystalline yeast pyrophosphatase, an enzyme which was shown to be 
specific for inorganic pyrophosphate (Heppel, 1955). This enzyme was used to show the presence in $\alpha$-casein of a disubstituted pyrophosphate link. Clearly, in the light of such conflicting evidence, any hypothesis on the way in which phosphorus is bound in casein must be treated with reserve.

\section{SUMMARY}

1. The action of purified phosphoprotein phosphatase and prostate phosphomonoesterase on various caseins and on a number of low-molecularweight phosphates was studied.

2. The phosphoprotein phosphatase preparation showed highest activity towards substrates which had a phosphate group esterified with aromatic hydroxyl groups, towards $\alpha$ - and $\beta$-caseins from cow's and goat's milk, inorganic pyrophosphate and acetyl phosphate; ribonucleotides and phosphoamides were hydrolysed to a smaller extent. Little or no activity was shown by the enzyme towards phosphodiesters, $O$-serine phosphate, $O$ threonine phosphate, $\alpha$ - and $\beta$-glycerol phosphate and disubstituted pyrophosphate.

3. Prostate phosphatase, with a very high activity towards $\beta$-glycerol phosphate and phenyl phosphate, liberated inorganic phosphorus only very slowly from $\alpha$-caseins and goat's $\beta$-casein, and not at all from cow's $\beta$-casein.

4. The results are discussed in relation to the nature of the phosphorus linkages in caseins.

The author thanks Miss M. Cumming and Miss E. S. Taylor for their technical assistance. He is indebted also to Dr W. Manson for the preparation of $N$-phosphoalanine, to Dr R. S. Wake for a generous sample of $N$-(phenylphosphoro)glycine and to Dr J. L. Peel for a gift of acetyl phosphate. Thanks are due also to Dr G. Weber and Dr D. T. Elmore for helpful discussions.

\section{REFERENCES}

Anson, M. L. (1938). J. gen. Physiol. 22, 79.

Bohren, H. U. (1955). Ph.D. Thesis: University of Berne. Crammer, J. L. \& Neuberger, A. (1943). Biochem. J. 37, 302. de Verdier, C. H. (1953). Acta chem. scand. 7, 196.
Dovey, A. \& Campbell, P. N. (1952). Nature, Lond., 169, 1014.

Dunn, M. S. (1949). Biochem. Prep. 1, 22.

Heppel, L. A. (1955). In Methods in Enzymology, vol. 2, p. 571. Ed. by Colowick, S. P. \& Kaplan, N. O. New York: Academic Press Inc.

Hipp, N. J., Groves, M. L., Custer, J. H. \& McMeekin, T. L. (1952). J. Dairy Sci. 35, 276.

Hofman, T. (1955). Abstr. 3rd Int. Congr. Biochem., Brussels, p. 26, nos. 4-9.

Hofman, T. (1958a). Biochem. J. 69, 135.

Hofman, T. (1958b). Nature, Lond., 181, 633.

Khorana, H. G. \& Todd, A. R. (1953). J.chem. Soc. p. 2257.

Lipmann, F. (1933). Biochem. Z. 262, 3.

Lipmann, F. \& Tuttle, L. C. (1945). J. biol. Chem. 159, 21.

London, M. \& Hudson, P. B. (1953). Arch. Biochem. Biophys. 46, 142.

Martin, J. B. \& Doty, D. M. (1949). Analyt. Chem. 21, 965.

Møller, K. M. (1955). Biochim. biophys. Acta, 16, 162.

Norberg, B. (1950). Acta chem. scand. 4, 1206.

Perlmann, G. E. (1952a). J. Amer. chem. Soc. 74, 3191.

Perlmann, G. E. (1952b). In Phosphorus Metabolism, vol. 2, p. 167. Ed. by McElroy, W. D. \& Glass, B. Baltimore: Johns Hopkins Press.

Perlmann, G. E. (1954a). Biochim. biophys. Acta, 13, 452.

Perlmann, G. E. (1954b). Nature, Lond., 174, 273.

Perlmann, G. E. (1955). Advanc. Protein Chem. 10, 1.

Plapinger, R. E. \& Wagner-Jauregg, T. (1953). J. Amer. chem. Soc. 75, 5757.

Plimmer, R. H. A. (1941). Biochem. J. 35, 461.

Plimmer, R. H. A. \& Bayliss, W. M. (1906). J. Physiol. 33, 439.

Plumel, M. (1948). Bull. Soc. Chim. biol., Paris, 30, 55.

Rathlev, T. \& Rosenberg, T. (1956). Arch. Biochem. Biophys. 65, 319.

Rimington, C. (1927). Biochem. J. 21, 1187.

Rimington, C. (1941). Biochem. J. 35, 321.

Strickland, K. P., Thompson, R. H. S. \& Webster, G. R. (1956). Arch. Biochem. Biophys. 64, 498.

Sundararajan, T. A. \& Sarma, P. S. (1954a). Biochem. J. $56,125$.

Sundararajan, T. A. \& Sarma, P. S. (1954b). Biochim. biophys. Acta, 13, 588.

Thoai, N.V., Roche, J. \& Pin, P. (1954). Bull. Soc. Chim. biol., Paris, 36, 483.

Warner, R. C. (1944). J. Amer. chem. Soc. 66, 1727.

Waugh, D. F. \& Hippel, P. H. von (1956). J. Amer. chem. Soc. 78, 4576.

Winnick, T. \& Scott, E. M. (1947). Arch. Biochem. Biophys. $12,201$. 